\title{
Intestinal Colonization Patterns of Staphylococci in Preterm Infants in Relation to Type of Enteral Feeding and Bacteremia
}

\author{
Veerle Cossey, ${ }^{1,2}$ Chris Vanhole, Jan Verhaegen, ${ }^{3}$ and Annette Schuermans ${ }^{2}$
}

\begin{abstract}
Objective: This study investigated the intestinal colonization with staphylococci in very low birth weight infants in relation to the type of enteral feeding and evaluated the intestine as potential source for staphylococcal bacteremia.

Patients and Methods: Infants born in the Level III neonatal intensive care unit of a university hospital with a gestational age below 32 weeks and/or birth weight below 1,500 g were included in a prospective, observational study. The infants received either preterm formula or mother's own milk, with random allocation to raw or pasteurized milk. Precise viable staphylococcal counts of serial fecal specimens were examined in the first 8 weeks of life. In the case of bloodstream infection, fecal and blood isolates of staphylococci were compared by antibiotypes or pulsed-field gel electrophoresis.

Results: One hundred fifty neonates, with a mean of 29 weeks of gestation and 1,260 g at birth, had 1,045 fecal samples analyzed and were found to be heavy carriers of staphylococci in the intestine with $10^{6}-10^{7}$ colonyforming units/g of feces from the first week of life. Colonization rate and patterns were not different in relation to the type of enteral feeding. In nearly $80 \%$ of 42 patients exhibiting a staphylococcal bloodstream infection, intestinal colonization retrieved a predominant strain that was different from the one recovered from the blood. Conclusions: In very low birth weight infants, predominance of staphylococci in the gut is not related to the type of enteral feeding. An endogenous origin of staphylococcal bloodstream infection seems to play a minor role.
\end{abstract}

\section{Introduction}

$\mathbf{P}$ RETERM INFANTS HAVE A HIGH RISK of serious infections during their stay in the neonatal intensive care unit (NICU). An immature immune system and an impaired gut and skin barrier make preterm infants prone to acquiring infections during their NICU stay. Frequent and prolonged exposure to broad-spectrum antibiotic agents and use of invasive devices add to this risk. Healthcare-acquired bloodstream infection (BSI) occurs in 16-36\% of infants with a birth weight (BW) below 1,500 g, caused by staphylococci in more than $70 \%$ of cases. ${ }^{1-4}$ Affected surviving infants have prolonged hospital stays and an increased risk for long-term morbidity such as chronic lung disease or cerebral palsy. ${ }^{5}$ These infections mostly arise from the patient's skin or indwelling central lines for parenteral nutrition; thus, strategies for prevention have focused entirely on this site. It is assumed that an endogenous origin plays a minor role in staphylococcal BSI. Mucosal colonization, however, can lead to sys- temic infections by translocation of bacteria from the intestinal lumen, enhanced by a poor gut motility, a delayed and sparse intestinal colonization, and an increased permeability through untight epithelial junctions. ${ }^{6}$

The process of intestinal maturation and colonization is promoted by the administration of enteral feeding, preferably early feeding with human milk. ${ }^{7}$ The use of raw mother's own milk feeding lowers the risk of BSI in preterm infants. ${ }^{8-10}$ Expressed human milk, however, is by itself a source of microorganisms, mainly staphylococci. Heat treatment can be applied to inactivate bacterial and viral contamination, but, by the lack of microbiological standards, practices vary among NICUs worldwide. It is not clear yet whether staphylococci in expressed milk can act as potential pathogens or, alternatively, are beneficial in establishing a healthy gut flora in preterm infants.

Because staphylococcal BSI is the most common cause of bacteremia in preterm infants, a better understanding of the possible endogenous source is important for the development

\footnotetext{
${ }^{1}$ Neonatal Intensive Care Unit, ${ }^{2}$ Department of Hospital Hygiene and Infection Control, and ${ }^{3}$ Department of Microbiology, University Hospitals Leuven, Leuven, Belgium.
} 
of additional prevention and management strategies. We undertook a prospective, observational study in order to describe the establishment and dynamics of the staphylococcal intestinal colonization in very low BW (VLBW) infants in relation to the type of enteral feeding, comparing raw with pasteurized mother's own milk and with formula milk. Second, we investigated whether the intestinal carriage of staphylococci is a possible pathway leading to BSI in preterm infants.

\section{Patients and Methods}

\section{Study design and patient enrollment}

All consecutive patients born before 32 weeks of gestation and/or below 1,500 g at birth, admitted within 24 hours of birth at the Level III NICU of the University Hospitals Leuven, Leuven, Belgium, were eligible for inclusion in the study, except for infants who died in the first 24 hours. Infants were followed up until 8 weeks of age or discharge from the NICU, whichever occurred first. Infants whose mothers intended to breastfeed were randomly assigned to receive either raw or pasteurized mother's own milk (Fig. 1). Human milk was expressed and transported under hygienic conditions following the principles of hazard analysis and critical control points and according to clear instructions to the mother regarding mechanical expression, milk collection, storage, and transport. If not used within 48 hours, the milk was frozen at $-20^{\circ} \mathrm{C}$ until used. Pasteurization consisted of the Holder process $\left(62.5^{\circ} \mathrm{C}\right.$ for 30 minutes) with a Sterifeed ${ }^{\circledR}$ S75 TES pasteurizer (Medicare Colgate Ltd., Cullompton, Devon, United Kingdom). If maternal milk was not available, preterm formula was given (PreNAN ${ }^{\circledR}$ [Nestlé Belgilux, Brussels, Belgium] or Nenatal ${ }^{\circledR}$ [Nutricia, Strombeek-Bever, Belgium]). No banked donor milk was used.

In both groups, enteral and parenteral nutrition was given according to the local nutritional protocol. Minimal trophic feeding was initiated at Day 2 after birth for infants with endotracheal ventilation, circulatory instability, or peripartal asphyxia, consisting of 12 boluses of $0.5 \mathrm{~mL}$ (if BW $<1,000 \mathrm{~g}$ ) or
$1 \mathrm{~mL}$ (if BW 1,000-1,500 g) given through a nasogastric tube for 5 days. Enteral feeding was started at Day 2 for all other infants: $1 \mathrm{~mL} / \mathrm{kg}$ given every 2 hours and increased by $12 \mathrm{~mL} / \mathrm{kg} /$ day up to $150 \mathrm{~mL} / \mathrm{kg}$ daily. Parenteral nutrition, provided through an umbilical venous catheter or a percutaneously inserted central venous catheter, consisted of glucose administration from Day 1 and amino acid and lipid administration initiated on Day 2 and Day 4, respectively. When enteral feeding reached a volume of $150 \mathrm{~mL} / \mathrm{kg}$ daily, parenteral nutrition was discontinued, and $\mathrm{MM}$ was fortified (Nutricia).

The institutional review board approved the study, and written informed parental consent was obtained.

\section{Bacteriological methods}

Fecal samples were obtained, into a clean preweighed container, between Days 0 and 2, Days 3 and 7, Days 8 and 11, Days 12 and 14, Days 15 and 18, Days 19 and 21, Days 22 and 28, Days 29 and 35, Days 36 and 42, Days 43 and 49, and Days 50 and 56. After weighing and vortex-mixing in a 1:1 ratio with VV9 $(1 \mathrm{~g} / \mathrm{L}$ Bacto Tryptone pancreatic digest of casein [BD Europe, Oxford, England] plus $8.5 \mathrm{~g} / \mathrm{L}$ sodium chloride [Merck ${ }^{\circledR}$, Darmstadt, Germany]), $1 \mu \mathrm{L}$ of the homogenized suspension, diluted $10^{2}$ - and $10^{4}$-fold, was inoculated onto Tryptone Soya agar and mannitol salt agar (both from Oxoid $^{\circledR}$, Cambridge, United Kingdom). Total colony-forming units (CFU) per gram of feces was manually counted after 48 hours of incubation at $37^{\circ} \mathrm{C}$ in a standard atmosphere. On the selective mannitol salt agar, different colonies of Staphylococcus species were identified on the basis of morphological characteristics (colony size, colony pigment, staphylococccal coagulase, and mannitol fermentation), and the different strains were stored in glycerol at $-80^{\circ} \mathrm{C}$. Milk samples were cultured weekly; $1 \mathrm{~mL}$ was plated onto blood agar and McConkey's agar and incubated for 48 hours.

In the case of BSI, pairs of strains isolated from blood and feces, sampled in the week before the onset of sepsis, were compared. The identification of the isolates and their sensitivity to antibiotics were determined using the Vitek system

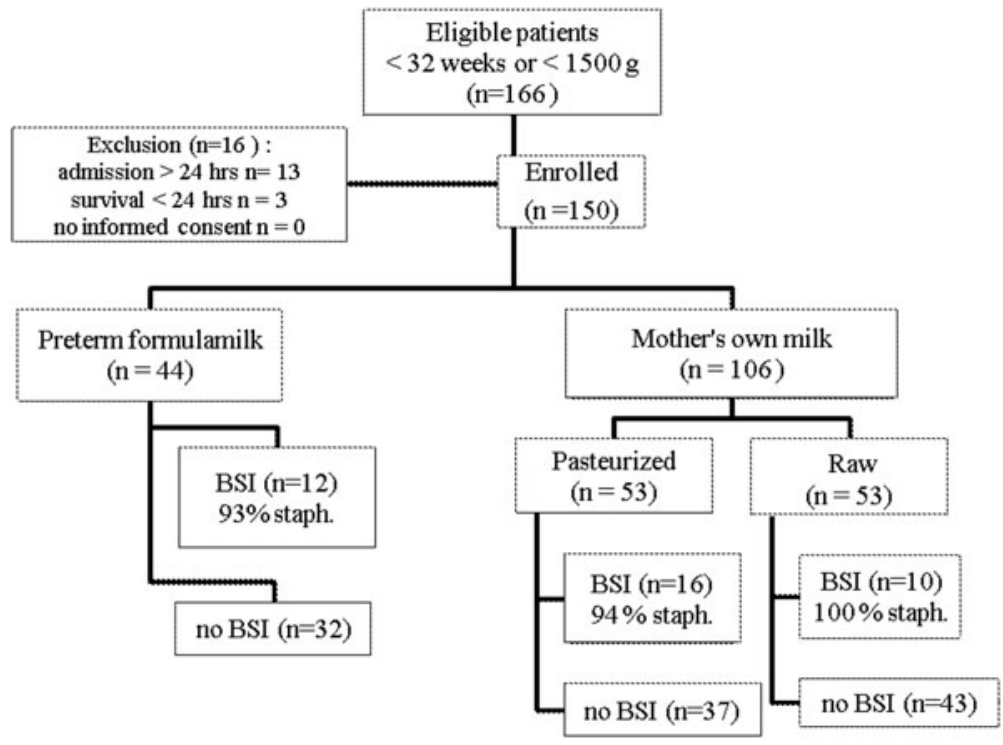

FIG. 1. Distribution of subjects and frequency of bloodstream infection (BSI). 
(bioMérieux, Marcy l'Etoile, France). A difference in antimicrobial susceptibility to two or more molecules indicated phenotypically distinct strains. In addition to phenotypic characteristics, pairs of strains were compared by pulsed-field gel electrophoresis (PFGE) analysis after SmaI macrorestriction with a CHEF-Mapper system (Bio-Rad Laboratories, Nazareth, Belgium). ${ }^{11}$ PFGE patterns were classified as follows: (1) group, including PFGE profiles showing six or fewer DNA fragment differences; (2) type, including PFGE profiles showing three or fewer DNA fragment differences; or (3) subtype, including any subclonal variant PFGE profile within a type. Patterns differing by more than three fragments were considered to be distinct strains. ${ }^{12,13}$

\section{Definitions and data collection}

Late-onset BSI, occurring more than 48 hours after birth, was defined as growth of a pathogen cultured from blood, obtained from a peripheral vein, combined with the acute onset of two or more predefined clinical signs and, in case of growth of coagulase-negative staphylococci (CoNS), with at least one laboratory parameter of systemic infection. ${ }^{14-16}$ For blood cultures, BacT / ALERT ${ }^{\circledR}$ PF bottles and a BacT/ALERT system (bioMérieux) were used. Baseline demographic and clinical characteristics of the infants and their mothers were recorded prospectively. Daily records were kept regarding markers of morbidity and treatment, including use of central venous catheter and exposure to antibiotics.

\section{Statistical analyses}

Normally distributed and nonparametric data are presented as mean \pm standard deviation values and medians with interquartile ranges. Skewed variables of bacterial counts were log-transformed in all analyses. Groups were compared using the Mann-Whitney $U$ test for the assessment of differences in continuous variables. A two-tailed $p$ value of $<0.05$ was considered statistically significant. Data were analyzed with software from Medcalc ${ }^{\circledR}$ (Mariakerke, Belgium).

\section{Results}

\section{Demographic and clinical data}

In a period of 18 months (ending in March 2008), 166 infants were eligible, of whom 150 were evaluated. One hundred six infants received predominantly mother's own milk, raw $(n=53)$ or pasteurized $(n=53)$, and 44 received exclusively preterm formula milk (Fig. 1).

Maternal and infant characteristics are shown in Table 1. There were no differences in BW, gestation, and catheter and antibiotic use among the three groups. Of all the infants, 93\% received one or more courses of antibiotics. Exposure for specific antibiotics was as follows: amoxicillin in $83 \%$ of infants; vancomycin, 46\%; amikacin, 89\%; piperacillintazobactam, 20\%; flucloxacillin, $9 \%$; cefotaxime, $5 \%$; and linezolid, 5\%. Enteral feeding was introduced at a median age of 3 days, irrespective of the type of milk. Human milk

Table 1. Characteristics of Study Population According to Feeding Group

\begin{tabular}{|c|c|c|c|}
\hline \multirow[b]{2}{*}{ Factor } & \multicolumn{3}{|c|}{ Group } \\
\hline & Raw $M M(\mathrm{n}=53)$ & Pasteurized $M M(\mathrm{n}=53)$ & Formula milk $(\mathrm{n}=44)$ \\
\hline \multicolumn{4}{|l|}{ Maternal $[n(\%)]$} \\
\hline Prolonged rupture of membranes (>18 hours) & $20(37)$ & $16(30)$ & $12(27)$ \\
\hline Histologic chorioamnionitis & $9(17)$ & $13(24)$ & $7(15)$ \\
\hline Use of antenatal steroids & $46(86)$ & $47(88)$ & $37(84)$ \\
\hline Use of antenatal antibiotics & $21(39)$ & $19(35)$ & $14(31)$ \\
\hline Cesarean delivery & $32(60)$ & $40(75)$ & $38(86)$ \\
\hline \multicolumn{4}{|l|}{ Infant $^{\mathrm{a}}$} \\
\hline Birth weight $(\mathrm{g})$ & $1,308 \pm 377$ & $1,269 \pm 458$ & $1,205 \pm 321$ \\
\hline Gestational age (weeks) & $29(27-31)$ & $30(28-31)$ & $30(28-31)$ \\
\hline Small for gestational age ( $<10$ th percentile) & $4(7)$ & $11(21)$ & $11(25)$ \\
\hline Apgar score $<7$ at 5 minutes & $2(3)$ & $3(5)$ & $3(6)$ \\
\hline CRIB score ${ }^{\mathrm{b}}$ & $1(0-3)$ & $2(1-5)$ & $2(1-3)$ \\
\hline Respiratory support (days) & $11(6-29)$ & $13(4-30)$ & $14(5-29)$ \\
\hline Length of NICU stay (days) ${ }^{c}$ & $39(24-62)$ & $40(23-72)$ & $43(29-64)$ \\
\hline Died during study period $(n)$ & 1 & 3 & 3 \\
\hline Antibiotic utilization ratio $(\%)^{\mathrm{d}}$ & 37 & 37 & 39 \\
\hline Day of first MM feeding & $3(2-4)$ & $3(2-3.2)$ & $\mathrm{NA}^{\mathrm{e}}$ \\
\hline Age achieved full enteral feeding (days) & $20(15-28)$ & $21(17-24)$ & $21(17-31)$ \\
\hline MM intake (mL/kg/day) & $54 \pm 32$ & $56 \pm 28$ & 0 \\
\hline Cumulative MM intake (L/kg) & $2.22 \pm 1.78$ & $2.29 \pm 1.65$ & 0 \\
\hline Proportion MM of total enteral intake (\%) & $86(69-95)$ & $86(63-92)$ & NA \\
\hline Central venous catheter use (days) & $17(13-24)$ & $17(12-23)$ & $19(14-26)$ \\
\hline
\end{tabular}

${ }^{a}$ Data are mean \pm standard deviation or median (interquartile range) values or $n(\%)$ as indicated.

${ }^{\mathrm{b}}$ Scores on the Clinical Risk Index for Babies (CRIB) range from 0 to 24 , with higher scores indicating a greater severity of illness. ${ }^{15}$

${ }^{c}$ Excluding patients deceased during the study period.

$\mathrm{d}$ (Total antibiotic days/total patient days) $\times 100$.

${ }^{\mathrm{e}}$ Median day of first formula milk feeding was 3 days (interquartile range, $2-5$ days).

$\mathrm{MM}$, mother's own milk; NA, not applicable; NICU, neonatal intensive care unit. 


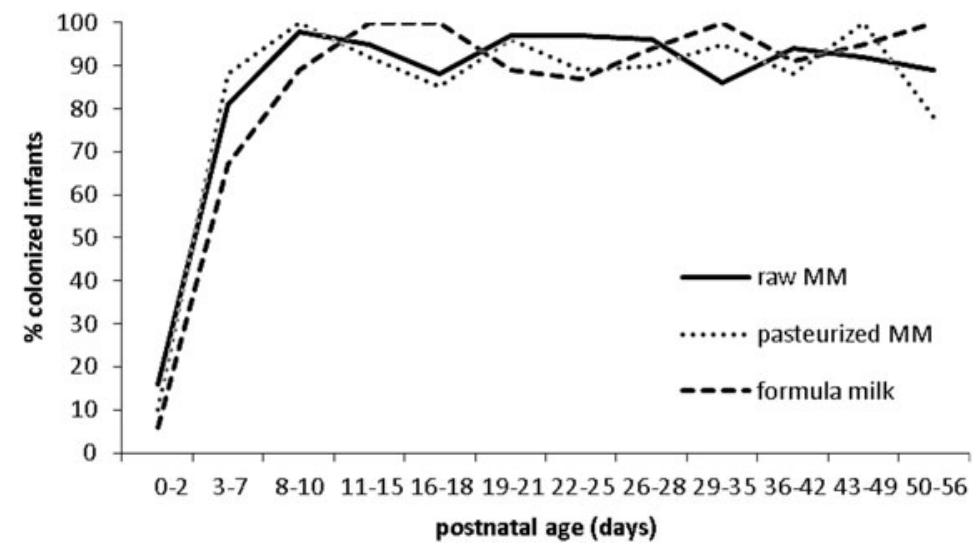

FIG. 2. Percentage of infants colonized in the gut with staphylococci in relation to postnatal age, by type of enteral feeding: raw mother's own milk (MM) ( $n=363$ fecal samples), pasteurized MM ( $n=341$ fecal samples), or formula milk $(n=341$ fecal samples). consumption was comparable in both mother's own milk groups, with $86 \%$ of total milk intake supplied as mother's own milk.

\section{Microbiological data}

From 150 infants included in the study, 1,045 fecal samples were analyzed; in 43 occasions no fecal specimen could be obtained in the predetermined interval, equally distributed over groups and over time. Morphological diversity of strains in fecal samples was low, and, on average, two morphologically distinct colonies were isolated per sample.

Intestinal colonization with staphylococci occurred in $11 \%$ of infants by the second day of life and increased rapidly to $79 \%$ at the end of the first week. Subsequently, between $88 \%$ and $96 \%$ of all infants were colonized with staphylococci (Fig. 2). The relapse in percentage of colonized infants in week 3 and week 5 may be partly explained by the concomitant use of antistaphylococcal antibiotics. The density of staphylococci reached $10^{6}-10^{7} \mathrm{CFU} / \mathrm{g}$ of feces by the end of the first week of life, and this reservoir remained stable during the study period (Fig. 3). The quantitative patterns were not significantly different in relation to the type of enteral feeding. Of 185 samples of raw mother's own milk, 98.3\% yielded bacterial isolates, mainly CoNS only (in $85 \%$ of samples with growth), Staphylococcus aureus (8\%), or enterococci (3\%). Postpasteurization and formula milk samples showed no growth.

Among 150 VLBW infants, 44 episodes of proven BSI occurred in 42 patients, an overall incidence of $28 \%$. The median age at onset was 15 days. The most common causative organisms were CoNS (75\%), especially Staphylococcus epidermidis and Staphylococcus capitis, and S. aureus (20\%). Only one Gram-negative BSI, due to Klebsiella oxytoca, and one candidemia occurred, in the pasteurized and formula milk- fed group, respectively. Antibiotic sensitivity was limited to vancomycin in eight of the 17 isolated strains of S. epidermidis, equally distributed among the study groups. All S. capitis strains were sensitive to vancomycin, erythromycin, and clindamycin. All but one $S$. aureus strains were sensitive to oxacillin or methicillin. At the onset of BSI, a central venous catheter was in place in 35 infants. From seven tips of 27 removed catheters, the same organism was isolated as that isolated from a peripheral blood culture.

\section{Relatedness between fecal and bloodstream isolates}

For the strains isolated in 42 patients with BSI, bacterial isolates from blood and feces, if available, were compared according to their species phenotype (21 cases), antimicrobial profile in the case of similar species (10 cases), or PFGE typing in the case of similar antimicrobial profile (three cases), as shown in Table 2. Overall, by combining the results of genotypic and phenotypic methods, in nine of the 34 pairs the same strain causing the BSI was present in the fecal culture of the week preceding the infectious episode. Seven pairs were classified as similar because of identical antimicrobial susceptibility, and two pairs were labeled thus by PFGE analysis (Fig. 4). Some pairs were not available for molecular typing because the strains were not kept in the laboratory or did not grow after frozen storage.

\section{Discussion}

We longitudinally evaluated the staphylococcal intestinal reservoir during the first 8 weeks of life in 150 preterm infants born at a gestational age below 32 weeks or BW below 1,500 g. An extensive colonization with staphylococci developed rapidly after birth, reaching a density of $10^{6}-10^{7} \mathrm{CFU} / \mathrm{g}$ of

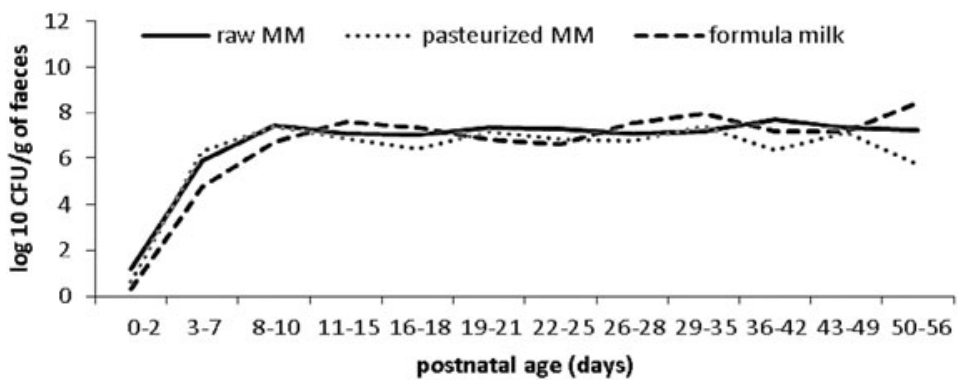

FIG. 3. Quantitative counts ( $\log _{10}$ colony-forming units [CFU]/g of feces) of staphylococci in relation to postnatal age, by type of enteral feeding: raw mother's own milk (MM) ( $n=363$ fecal samples), pasteurized MM ( $n=341$ fecal samples), or formula milk ( $n=341$ fecal samples). Data are mean values. 
Table 2. Pairs of Bacterial Isolates from Blood and Feces in Patients with Bloodstream Infection

\begin{tabular}{|c|c|c|c|}
\hline Subgroup & $\begin{array}{l}\text { Bacterial strains in } \\
\text { blood culture (BSI) }\end{array}$ & $\begin{array}{l}\text { Predominant fecal isolates } \\
<7 \text { days before onset of BSI }\end{array}$ & $\begin{array}{c}\text { Classification of pairs different/ } \\
\text { similar (SI, AP, PFGE) }\end{array}$ \\
\hline \multirow[t]{9}{*}{ Raw maternal milk } & S. epidermidis & S. epidermidis & Similar SI, similar AP \\
\hline & S. aureus & Serratia marcescens & Different SI \\
\hline & S. epidermidis & S. aureus & Different SI \\
\hline & S. capitis & S. capitis & Similar SI, similar AP \\
\hline & S. epidermidis & Enterococcus faecalis & Different SI \\
\hline & S. capitis & S. epidermidis & Different SI \\
\hline & Staphylococcus hominis & S. epidermidis & Different SI \\
\hline & S. capitis & S. aureus & Different SI \\
\hline & S. epidermidis & E. faecalis & Different SI \\
\hline \multirow[t]{15}{*}{ Pasteurized maternal milk } & S. epidermidis & E. faecalis & Different SI \\
\hline & K. oxytoca & S. epidermidis & Different SI \\
\hline & S. epidermidis & S. epidermidis & Similar SI, different AP \\
\hline & Staphylococcus lugdunensis & S. epidermidis & Different SI \\
\hline & S. epidermidis & E. faecalis/Acinetobacter spp. & Different SI \\
\hline & S. capitis & Enterococcus faecium & Different SI \\
\hline & S. aureus & S. aureus & Similar SI, similar AP \\
\hline & S. capitis & S. capitis & $\begin{array}{l}\text { Similar SI, similar AP, } \\
\text { similar PFGE profile }\end{array}$ \\
\hline & S. capitis & Serratia marcescens & Different SI \\
\hline & CoNS & S. aureus & Different SI \\
\hline & S. aureus & S. aureus & Similar SI, similar AP \\
\hline & S. aureus & S. epidermidis & Different SI \\
\hline & S. capitis & S. capitis & Similar SI, similar AP \\
\hline & Staphylococcus warneri & E. faecalis & Different SI \\
\hline & S. capitis & S. aureus/S. epidermidis & Different SI \\
\hline \multirow[t]{10}{*}{ Formula milk } & S. epidermidis & S. epidermidis & Similar SI, similar AP \\
\hline & S. epidermidis & S. epidermidis & $\begin{array}{l}\text { Similar SI, similar AP, } \\
\text { similar PFGE profile }\end{array}$ \\
\hline & S. epidermidis & S. epidermidis & Similar SI, different AP \\
\hline & S. epidermidis & S. epidermidis & $\begin{array}{l}\text { Similar SI, similar AP, } \\
\text { different PFGE profile }\end{array}$ \\
\hline & S. aureus & E. faecalis & Different SI \\
\hline & S. aureus & $\begin{array}{l}\text { S. epidermidis/E. faecalis/ } \\
\text { E. faecium }\end{array}$ & Different SI \\
\hline & S. aureus & S. aureus & Similar SI, different AP \\
\hline & S. capitis & S. epidermidis & Different SI \\
\hline & S. capitis & S. aureus & Different SI \\
\hline & S. epidermidis & S. epidermidis & Similar SI, similar AP \\
\hline
\end{tabular}

AP, antimicrobial profile; BSI, bloodstream infection; CoNS, coagulase-negative staphylococci; PFGE, pulsed-field gel electrophoresis; SI, species identification.

FIG. 4. Pulsed-field gel electrophoresis (PFGE) profiles of strains of staphylococci isolated from three patients with similar fecal and blood isolates, according to species identification and antibiotic profile. MM, mother's own milk; $\mathrm{R}$, resistant.

\begin{tabular}{|l|l|l|l|c|c|c|c|c|c|}
\hline Patient & type of feeding & sample & identification & $\begin{array}{c}\text { Coagulase } \\
\text { test }\end{array}$ & oxacillin & $\begin{array}{c}\text { Nuc } \\
\text { gene }\end{array}$ & $\begin{array}{l}\text { mecA } \\
\text { gene }\end{array}$ & 16S & PFGE \\
\hline patient 1 & pasteurized MM & blood & S.capitis & - & $\mathrm{R}$ & - & + & + & $\mathrm{Ala}$ \\
\hline & & faeces & S.capitis & - & $\mathrm{R}$ & - & + & + & $\mathrm{Ala}$ \\
\hline patient 2 & formula milk & blood & S.epidermidis & - & $\mathrm{R}$ & - & + & + & $\mathrm{Blb}$ \\
\hline & & faeces & S.epidermidis & - & $\mathrm{R}$ & - & + & + & $\mathrm{Bla}$ \\
\hline patient 3 & formula milk & blood & S.epidermidis & - & $\mathrm{R}$ & - & + & + & $\mathrm{A}$ \\
\hline & & faeces & S.epidermidis & - & $\mathrm{R}$ & - & + & + & $\mathrm{D}$ \\
\hline
\end{tabular}

MM : mother's own milk - R : resistant - PFGE : pulsed field gel electrophoresis
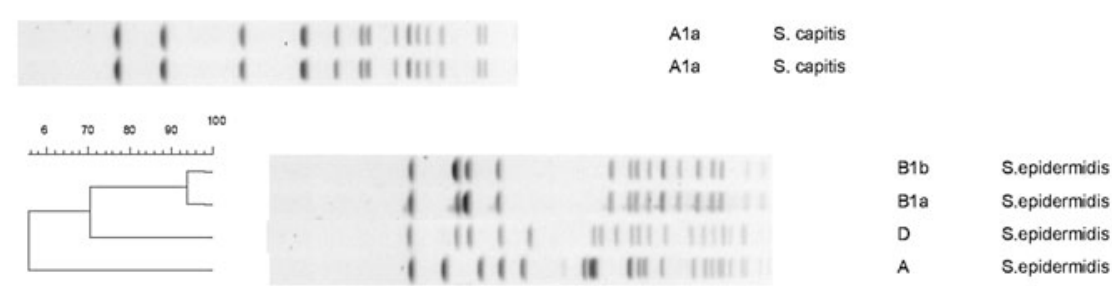
feces by the first week of life. This abundant reservoir persisted in the next weeks, with $88-96 \%$ of all infants colonized, and was not influenced by the type of enteral feeding.

Previous studies in preterm infants showed that the development of the gut microbiota is delayed and that bacterial diversity is low. With classical culture techniques, between two and five species were identified during the first 30 days of life in extremely low birth weight infants. ${ }^{17}$ By using direct molecular fingerprinting, a limited number of at most four species was found after 30 days and nine by week 6 of life, or a mean of 3.25 species per preterm infant. ${ }^{18,19}$ Some studies specifically reported on staphylococcal colonization patterns in the gut of preterm infants. In two culture-based studies, staphylococci were sparsely found in $35-59 \%$ of infants, ${ }^{17,20}$ but other studies identified larger intestinal reservoirs of staphylococci, colonizing $77-100 \%$ of infants, in line with the results of this study. ${ }^{17,21-23}$ Molecular approaches, including techniques like fluorescence in situ hybridization and 16S rRNA gene sequencing, have not yet identified new data on the staphylococcal colonization patterns. Most studies describe a predominance of staphylococci in the microbiota of preterm infants. ${ }^{18,24,25}$

The impact of the type of enteral feeding on the development and density of the staphylococcal gut colonization has not been extensively studied. It is well known, from studies in term infants, that factors in human milk such as lactoferrin and oligosaccharides, acting as prebiotics, stimulate the growth of bifidobacteria. In contrast, formula feeding is associated with an abundance of Enterobacteriaceae, Bacteroides species, and Clostridium difficile. ${ }^{26,27}$ In preterm infants, the impact of the diet is less pronounced. ${ }^{17,25}$ Because human milk contains up to $10^{9}$ live bacteria/L, with a predominance of CoNS and $S$. aureus, ${ }^{28,29}$ we speculated that different milk diets with different bacterial contents could have an effect on the staphylococcal colonization patterns. We compared expressed, raw mother's own milk, containing $10^{6}-10^{8} \mathrm{CFU}$ of staphylococci/L, with pasteurized mother's own milk and formula milk, both not containing any cultivable bacteria. We found that the frequency, density, and stability of staphylococcal colonization was not influenced by the type of enteral feeding and thus by the ingestion of staphylococcal bacteria.

The pathways of acquisition of intestinal staphylococcal carriage in preterm infants remain to be further elucidated. If enteral intake of milk is not the main entry mechanism and bacteriological composition of milk does not influence the density of the colonization, as is shown in this study, the NICU environment, including the hands and skin of the caregivers and parents, most probably plays a greater role in the establishment of the endogenous gut reservoir. These strains have the potential to be more virulent compared with staphylococci derived from the mother via the milk. Our data show, however, no difference in sensitivity patterns of the CoNS or S. aureus strains causing BSI among the study groups.

This study also evaluated the correlation between staphylococcal isolates of blood and of the gastrointestinal tract. In all episodes of BSI, an abundant staphylococcal reservoir could be demonstrated at the time of infection. In nine of 34 episodes of staphylococcal BSI (26\%), intestinal colonization retrieved a strain of staphylococci similar to the infecting pathogen. This association between intestinal and BSI strains may suggest translocation from the enteric reservoir but does not necessarily prove causality. In experimental studies with breast-fed rats, ${ }^{30}$ translocation of staphylococci from the mucosal gastrointestinal site to mesenteric lymph nodes and subsequently to the bloodstream has been documented, as well as in clinical studies with adult surgical patients ${ }^{31}$ and allogeneic bone marrow transplant recipients. ${ }^{32,33}$ Such a mechanism has not yet been reported in neonates. Staphylococcal BSI in preterm infants may be associated with various sites of acquisition; the mucosal colonization of the gut preceding bacterial translocation as one possible route. ${ }^{6,34}$ The origin may be another site of carriage such as skin or catheter, acquired by an exogenous pathway of colonization from the NICU environment or the healthcare workers or parents. When developing preventive strategies against invasive staphylococcal BSI in preterm infants, a broad approach is needed because of this complex pathogenesis. Infection control practices focus on hand hygiene and appropriate catheter care to prevent cross-infection between infants. Additionally, kangaroo mother care reduces the risk of nosocomial infection by colonizing infants with their mother's skin flora, being less virulent than environmental strains. ${ }^{35}$ As pointed out by our results, interventions such as pasteurization of mother's own milk, and hence avoiding direct enteral intake of staphylococci, does not decrease or delay staphylococcal intestinal colonization. Whether this heat-treated milk has an impact on selection of more virulent and invasive staphylococcal strains leading to BSI needs to be explored in clinical studies.

Several limitations can be addressed regarding this study. First, culture-based quantitative measurements were applied instead of molecular tools because this method was more feasible for a large study group with frequent sampling, and, moreover, an assessment of the global diversity of the fecal microbiota, including noncultivable bacteria, was beyond the aim of this study. Second, we did not assess other sites of colonization such as skin, catheter hub, or other mucosal sites. Third, only morphologically different strains of staphylococci in the gut, isolated around the time of BSI, were typed and matched with blood isolates, which could have underestimated a possible correlation.

In summary, an abundant staphylococcal intestinal reservoir develops in the gut of preterm infants. Using different milk diets as tools to influence the colonization process does not modify the prevalence, density, or stability of the staphylococcal colonization. Most cases of staphylococcal bacteremia are independent of intestinal carriage, suggesting an exogenous pathway of contamination, underlying the role of hospital infection control measures.

\section{Acknowledgments}

We are indebted to the nursing staff for the collection of samples, to the staff of the Departments of Infection Control and Microbiology of the University Hospitals Leuven for their cooperation, and to O. Denis and R. De Ryck of the Molecular Microbiology Department of ULB Brussels for the PFGE genotyping.

\section{Disclosure Statement}

No competing financial interests exist.

\section{References}

1. Brodie S, Sands K, Gray J, et al. Occurrence of nosocomial bloodstream infections in six neonatal intensive care units. Pediatr Infect Dis J 2000;19:56-65. 
2. Makhoul IR, Sujov $P$, Smolkin T, et al. Pathogen-specific early mortality in very low birth weight infants with late-onset sepsis: A national survey. Clin Infect Dis 2005;40:218-224.

3. Stoll BJ, Hansen N, Fanaroff A, et al. Late-onset sepsis in very low birth weight neonates: The experience of the NICHD Neonatal Research Network. Pediatrics 2002;110:285-291.

4. Stoll BJ, Hansen NI, Bell EF, et al. Neonatal outcomes of extremely preterm infants from the NICHD Neonatal Research Network. Pediatrics 2010;126:443-456.

5. Schlapbach LJ, Aebischer M, Adams M, et al. Impact of sepsis on neurodevelopmental outcome in a Swiss National Cohort of extremely premature infants. Pediatrics 2011;128:e348-e357.

6. Caicedo R, Schanler R, Li N, et al. The developing intestinal ecosystem: Implications for the neonate. Pediatr Res 2005;58: 625-628.

7. Schanler RJ, Shulman RJ, Lau C. Feeding strategies for premature infants: Beneficial outcomes of feeding fortified human milk versus preterm formula. Pediatrics 1999;103: 1150-1157.

8. Hylander MA, Strobino DM, Dhanireddy R. Human milk feedings and infection among very low birth weight infants. Pediatrics 1998;102:e38.

9. Schanler R. Evaluation of the evidence to support current recommendations to meet the needs of premature infants: The role of human milk. Am J Clin Nutr 2007;85:625S-628S.

10. Ronnestad A, Abrahamsen TG, Medbo S, et al. Late-onset septicemia in a Norwegian National Cohort of extremely premature infants receiving very early full human milk feeding. Pediatrics 2005;115:e269-e276.

11. Denis O, Magdalena J, Deplano A, et al. Molecular epidemiology of resistance to macrolides-lincosamidesstreptogramins in methicillin-resistant Staphylococcus aureus causing bloodstream infections in patients admitted to Belgian hospitals. J Antimicrob Chemother 2002;50:755-757.

12. Deplano A, Witte W, Van Leeuwen WJ, et al. Clonal dissemination of epidemic methicillin-resistant Staphylococcus aureus in Belgium and neighboring countries. Clin Microbiol Infect 2000;6:239-245.

13. Tenover FC, Arbeit RD, Goering RV, et al. Interpreting chromosomal DNA restriction patterns produced by pulsedfield gel electrophoresis: Criteria for bacterial strain typing. J Clin Microbiol 1995;33:2233-2239.

14. Gastmeier P, Geffers C, Schwab F, et al. Development of a surveillance system for nosocomial infections: The component for neonatal intensive care units in Germany. J Hosp Infect 2004;57:126-131.

15. Horan T, Andrus M, Dudeck M. CDC/NHSN surveillance definition of health care-associated infection and criteria for specific types of infections in the acute care setting. Am J Infect Control 2008;26:309-332.

16. Modi N, Doré C, Saraswatula A, et al. A case definition for national and international neonatal bloodstream infection surveillance. Arch Dis Child Fetal Neonatal Ed 2009;94:F8-F12.

17. Gewolb IH, Schwalbe RS, Taciak VL, et al. Stool microflora in extremely low birthweight infants. Arch Dis Child Fetal Neonatal Ed 1999;80:F167-F173.

18. Jacquot A, Neveu D, Aujoulat F, et al. Dynamics and clinical evolution of bacterial gut microflora in extremely premature patients. J Pediatr 2011;158:390-396.

19. Magne F, Abely M, Boyer F, et al. Low species diversity and high interindividual variability in faeces of preterm infants as revealed by sequences of $16 \mathrm{~S}$ rRNA genes and PCR temporal temperature gradient gel electrophoresis profiles. FEMS Microbiol Ecol 2006;57:128-138.
20. Blakey JL, Lubitz L, Barnes GL, et al. Development of gut colonisation in pre-term neonates. J Med Microbiol 1982; 15:519-529.

21. Eastick K, Leeming J, Bennett D, et al. Reservoirs of coagulase negative staphylococci in preterm infants. Arch Dis Child Fetal Neonatal Ed 1996;74:F99-F104.

22. Sakata H., Yoshioka H, Fujita K. Development of the intestinal flora in very low birth weight infants compared to normal full-term newborns. Eur J Pediatr 1985;144:186-190.

23. Westerbeek $E$, van den Berg $A$, Lafeber $H$, et al. The intestinal bacterial colonisation in preterm infants: A review of the literature. Clin Nutr 2006;25:361-368.

24. Björkqvist M, Liljedahl M, Zimmermann J, et al. Colonization pattern of coagulase negative staphylococci in preterm neonates and the relation to bacteremia. Eur J Clin Microbiol Infect Dis 2010;29:1085-1093.

25. Björkström M, Hall L, Söderlund S, et al. Intestinal flora in very low birth weight infants. Acta Paediatr 2009;98:1762-1767.

26. Cilieborg MS, Boye M, Sangild PT. Bacterial colonization and gut development in preterm neonates. Early Hum Dev 2012;88(Suppl 1):S41-S49.

27. Penders J, Thijs C, Vink C, et al. Factors influencing the composition of the intestinal microbiota in early ilnfancy. Pediatrics 2006;118:511-521.

28. Landers S, Updegrove K. Bacteriological screening of donor human milk before and after Holder pasteurization. Breastfeed Med 2010;5:117-121.

29. Lindemann PC, Foshaugen I, Lindemann R. Characteristics of breast milk and serology of women donating breast milk to a milk bank. Arch Dis Child Fetal Neonatal Ed 2004;89: F440-F441.

30. Yajima M, Nakayama M, Hatano S, et al. Bacterial translocation in neonatal rats: the relation between intestinal flora, translocated bacteria, and influence of milk. J Pediatr Gastroenterol Nutr 2001;33:592-601.

31. MacFie J, Boyle C, Mitchell C, et al. Gut origin of sepsis: A prospective study investigating associations between bacterial translocation, gastric microflora, and septic morbidity. Gut 1999;45:223-228.

32. Costa SF, Miceli MH, Anaissie EJ. Mucosa or skin as source of coagulase-negative staphylococcal bacteraemia? Lancet Infect Dis 2004;4:278-286.

33. Ford C, Reilly W, Wood J, et al. Oral antimicrobial prophylaxis in bone marrow transplant recipients: Randomized trial of ciprofloxacin versus ciprofloxacin-vancomycin. Antimicrob Agents Chemother 1998;42:1402-1405.

34. Duffy LC. Interactions mediating bacterial translocation in the immature intestine. J Nutr 2000;130(SS Suppl):432S436S.

35. Conde-Agudelo A, Belizan J, Diaz-Rossello J. Kangaroo mother care to reduce morbidity and mortality in low birthweight infants. Cochrane Database Syst Rev 2011;(3): CD002771.

Address correspondence to: Veerle Cossey, $M D$

Departments of Hospital Hygiene and Infection Control and of Neonatology

University Hospitals Leuven Herestraat 49

3000 Leuven, Belgium

E-mail: veerle.cossey@uzleuven.be 